\title{
PERBEDAAN COMPLIANCE COST SEBELUM DAN SESUDAH PENGgUNAAN APLIKASI E-FILING PADA WAJIB PAJAK BADAN PENGGUNA $E$-FILING
}

\author{
Vania Wimayo \\ Universitas Airlangga \\ Email: vaniawimayo92@gmail.com
}

\begin{abstract}
ABSTRAK
Tujuan dari penelitian ini adalah untuk mengetahui perbedaan compliance cost yang dikeluarkan sebelum dan sesudah penggunaan aplikasi E-Filing bagi wajib pajak badan pengguna $E$ Filing. E-Filing adalah sistem pelaporan SPT yang dibuat oleh Dirjen Pajak yang memberikan kemudahan bagi wajib pajak dalam pembuatan dan penyerahan laporan SPT kepada Dirjen Pajak. Hipotesis dalam penelitian ini di diuji menggunakan Wilcoxon match pairs test. Hasilnya menunjukkan bahwa compliance cost sesudah penggunaan e-filing berbeda dengan sebelumnya, dimana compliance cost menjadi lebih rendah.
\end{abstract}

\section{Kata Kunci : E-Filing, Compliance Cost, Dirjen Pajak, Wilcoxon match pairs test}

\section{PENDAHULUAN}

\section{Latar Belakang Penelitian}

Sistem perpajakan di Indonesia menganut sistem Self Assesment. Wajib pajak di beri wewenang untuk menghitung, membayar dan melaporkan pajaknya sendiri. Sistem tersebut mendorong wajib pajak untuk transparan dan tanggung jawab atas perhitungan pajaknya. Di sisi lain fiskus juga harus memantau kepatuhan wajib pajak. Pemantauan pajak yang rendah dan pengembangan keuangan menengah memberi kontribusi pada usaha kecil dan kecil menengah yang cukup besar dimana respon transparansi terhadap pajak itu penting. (Pappadá and Zylberberg, 2017)

Dengan semakin majunya kehidupan ekonomi masyarakat saat ini maka semakin meningkat juga kewajiban masyarakat untuk membayar pajak. Masyarakat di zaman sekarang menginginkan pelayanan yang cepat, mudah, murah dan berkualitas. Itulah yang juga masyarakat inginkan dalam pelayanan perpajakan.

Mengingat adanya tuntutan dari masyarakat akan adanya pelayanan yang berkualitas dan efektif, maka Dirjen Pajak berusaha melakukan modernisasi pada sistem pelayanan perpajakan

Dengan tujuan modernisasi seperti yang disebutkan di atas, maka Dirjen Pajak dituntut untuk membuat program - program baru yang bisa meningkatkan kepatuhan dan kepercayaan wajib pajak terhadap Dirjen Pajak. Temuan menunjukkan bahwa kualitas pelayanan perpajakan merupakan penentu penting bagi penggunaan sistem pajak online yang memberikan relevansi dengan sistem administrasi perpajakan. (Mustaphaa et.al,2014)

Salah satu program yang saat ini sedang menjadi topik yang hangat adalah $e$-Filing. Dalam penelitian sebelumnya dijelaskan bahwa pengarsipan elektronik (E-Filing) adalah aplikasi penting yang mengotomatisasi proses terkait pajak dalam upaya untuk meningkatkan efisiensi dalam menilai dan mengumpulkan informasi pajak. Ini memiliki potensi untuk memperbaiki layanan pengarsipan pajak sementara pada saat yang sama mengurangi biaya bagi pembayar pajak dan agen pengumpul pajak (Fu et.al, 2006). E-Filing merupakan suatu cara penyampaian SPT 
Tahunan secara elektronik yang dilakukan secara online dan real time melalui internet pada website Direktorat Jenderal Pajak (www.pajak.go.id). Melalui e-Filing, Wajib Pajak dapat mengirimkan SPT dari mana saja selama bisa mengakses www.pajak.go.id dan dalam 24 jam sehari, 7 hari seminggu

Penerimaan e-filing oleh masyarakat secara signifikan dipengaruhi oleh kepercayaan mereka terhadap penyedia e-filing yang mereka gunakan untuk menyelesaikan dan menyerahkan pajak mereka secara online. Kepercayaan penyedia e-file telah terbukti mengurangi risiko yang dirasakan warga negara dan meningkatkan kemungkinan penggunaan mereka. Ini menyoroti, baik untuk lembaga pemerintah maupun penyedia layanan efiling sebenarnya, fakta bahwa hubungan saling percaya dengan warga negara selama proses e-filing sangat penting dan hubungan yang dibangun harus dipupuk. (Schaupp et.al,2010)

E-filing juga memiliki potensi penghematan biaya pada sisi sektor publik dari sistem perpajakan, mengurangi biaya administrasi perpajakan. Secara khusus, komputerisasi semua catatan pajak dapat mengurangi kesalahan dan mengurangi upaya otoritas pajak dalam memilah dan menganalisis file pajak, di samping potensi pengurangan korupsi dan interaksi informal antara wajib pajak dan petugas pajak. (Yilmaz and Coolidge, 2013). Dukungan pemerintah menentukan harapan perilaku. Dengan demikian, pemerintah harus mendukung pengguna akhir dengan panduan untuk mendapatkan instruksi dan memberikan layanan bantuan teknis $24 / 7$ untuk membantu mereka saat mengisi pajak mereka secara online atau saat sistem mogok. Pemerintah harus menerapkan strategi proaktif untuk memberitahu warga negara tentang manfaat pengajuan pajak pendapatan melalui saluran online. (Carter et al,2011)

Namun, ternyata wajib pajak yang menggunakan e-Filing masih dibilang sangat rendah. Hal ini dibuktikan oleh Penelitian sebelumnya yang menjelaskan bahwa walaupun pelaporan pajak elektronik semakin populer di kalangan wajib pajak, namun kebanyakan orang menggunakan sistem ini untuk mendapatkan pengalaman mengirimkan pajak secara elektronik dengan kemampuan navigasi yang buruk dan rasa tidak yakin tentang fungsionalitas, keamanan, dan perhatian atas informasi sensitif mereka, yang dapat menyebabkan

(Santhanamery,2012)

$$
\text { pengguna }
$$

menyerah.

Pada tahun 2017 wajib pajak di Indonesia yang memanfaatkan e-Filing baru berjumlah 6.931 wajib pajak. Padahal hampir semua warga Indonesia sudah tidak asing dengan sistem yang berbasis internet.

Hal ini tentunya menarik diteliti kenapa e-Filing belum populer di kalangan masyarakat, terutama para wajib pajak. Padahal, e-Filing diharapkan bisa mengurangi biaya - biaya yang harus dikeluarkan wajib pajak untuk memenuhi kewajiban perpajakannya (cost of compliance).

Untuk mempermudah pembahasan yang ada, maka penulisan ini dibagi menjadi yang pertama pendahuluan, lalu landasan teori dan pembentukan hipotesis, setelahnya membahas metodologi penelitian, dan yang terakhir adalah hasil penelitian serta Kesimpulan dan keterbatasan penelitian

\section{LANDASAN TEORI}

\section{Aplikasi $e$-Filing}

$e$-Filing adalah sistem pelaporan SPT yang dibuat oleh Dirjen Pajak yang memberikan kemudahan bagi wajib pajak dalam pembuatan dan penyerahan laporan SPT kepada Dirjen Pajak (lebih cepat, lebih murah, lebih mudah, dan kapan saja). Dasar keputusan penyampaian SPT secara elektronik terdapat dalam Surat Keputusan No. 88 mengenai pelaporan SPT secara elektronik pada bulan Mei 2004.

$e$-Filing ini dibuat Dirjen Pajak untuk memenuhi kebutuhan wajib pajak akan pelayanan yang cepat dan berkualitas dan yang pasti rendah biaya, antara lain biaya pemrosesan laporan pajak, biaya administrasi pajak. Tujuan utama layanan pelaporan pajak secara e-Filing ini adalah :

1. Membantu para Wajib Pajak untuk menyediakan fasilitas pelaporan SPT secara elektronik (via internet) kepada 
wajib pajak, sehingga wajib pajak orang pribadi dapat melakukannya dari rumah atau tempatnya bekerja, sedangkan wajib pajak badan dapat melakukannya dari lokasi kantor atau usahanya. Hal ini akan dapat membantu memangkas biaya dan waktu yang dibutuhkan oleh Wajib Pajak untuk mempersiapkan, memproses dan melaporkan SPT ke kantor pajak secara benar dan tepat waktu.

2. Dengan cepat dan mudahnya pelaporan pajak, berarti juga akan memberikan dukungan kepada kantor pajak dalam hal percepatan penerimaan laporan SPT dan perampingan kegiatan administrasi, pendataan, distribusi dan pengarsipan laporan SPT.

3. Saat ini tercatat lebih dari 10 juta Wajib Pajak di Indonesia, dengan cara pelaporan yang manual tidak mungkin akan dapat ditingkatkan pelayanan terhadap para WP tersebut. Maka dengan e-Filing, dimana sistem pelaporan menjadi mudah dan cepat, diharapkan jumlah Wajib Pajak dapat meningkat lagi dan penerimaan negara tercapai.

Kelebihan dari aplikasi $e$-Filing, yaitu :

1. Penyampaian SPT dapat dilakukan secara cepat, aman, dan kapan saja.

2. Murah, tidak dikenakan biaya pada saat pelaporan SPT.

3. Penghitungan dilakukan secara tepat karena menggunakan sistem komputer.

4. Kemudahan dalam mengisi SPT, karena pengisian SPT dalam bentuk wizard.

5. Data yang disampaikan WP selalu lengkap karena ada validasi pengisian SPT.

6. Ramah lingkungan dengan mengurangi penggunaan kertas.

7. Dokumen pelengkap (Fotokopi Formulir 1721 A1/A2 atau bukti potong $\mathrm{PPh}$, SSP Lembar ke-3 $\mathrm{PPh}$
Pasal 29, Surat Kuasa Khusus, Perhitungan PPh terutang bagi Wajib Pajak Kawin Pisah Harta dan/atau Mempunyai NPWP Sendiri, Fotokopi Bukti Pembayaran Zakat) tidak perlu dikirim lagi kecuali diminta oleh KPP melalui Account Representative (AR).

Selain itu, jaminan kerahasiaan dari SPT yang dilaporkan secara $e$-Filing sangat tinggi, karena SPT yang dikirimkan akan di encrypted sehingga terjamin kerahasiaannya.

Dalam aplikasi $e$-Filing juga ada layanan - layanan yang tersedia, yang bisa digunakan oleh wajib pajak, yaitu:

1. Layanan permohonan e-FIN

WP harus melakukan proses permohonan untuk memperoleh eFIN. E-FIN merupakan nomor identitas Wajib Pajak yang mengajukan permohonan untuk melaksanakan $e$-Filing.

2. Layanan pendaftaran pengguna $e$ Filing

Wajib Pajak diwajibkan untuk melakukan registrasi melalui situs $e$ Filing paling lama 30 (tiga puluh) hari kalender sejak diterbitkannya eFIN.

3. Layanan permintaan kode verifikasi (passcode)

Setiap kali wajib pajak akan melakukan transaksi pengiriman SPT, maka wajib pajak harus mengisikan kode verifikasi yang akan dikirimkan oleh sistem $e$-Filing melalui $e$-mail milik wajib pajak.

4. Layanan pengisian SPT

WP melakukan perekaman data SPT melalui website sesuai dengan formulir SPT yang digunakan.

5. Layanan pengiriman SPT

WP mengirimkan SPT secara elektronik dari e-Filing. WP yang 
data SPT nya berhasil terkirim melalui $e$-Filing akan memperoleh Bukti Penerimaan Elektronik yang merupakan tanda terima penyampaian SPT Tahunan.

\section{Cost of Compliance}

Cost of compliance atau disebut juga dengan biaya kepatuhan adalah biaya yang harus dikeluarkan oleh wajib pajak untuk memenuhi kewajiban perpajakannya. Biaya kepatuhan tidak termasuk jumlah biaya yang dikeluarkan untuk melunasi pajak yang terutang (Main,2012)

Biaya kepatuhan berhubungan juga dengan tingkat kepatuhan karenanya dapat meningkatkan tingkat penghindaran pajak (Erard and Ho, 2003).

Cost of compliance dapat dibagi menjadi beberapa bagian yaitu :

1. Direct money cost, yaitu seluruh biaya yang dikeluarkan oleh wajib pajak untuk memenuhi hak dan kewajibannya dan bisa diukur dalam nilai uang. Contohnya biaya pegawai bagian pajak, biaya jasa konsultan pajak, biaya transportasi ke KPP, biaya pengadaan dokumen pajak, dll.

2. Time cost, yaitu biaya berupa waktu yang harus dikorbankan oleh wajib pajak untuk memenuhi kewajiban dan hak perpajakannya. Contohnya waktu untuk mengisi formulir pajak, waktu untuk pergi ke kantor pajak, dll.

\section{Hipotesis Penelitian} adalah :

Adapun hipotesis dari penelitian ini

$\mathrm{H}_{0}$ : Compliance cost sebelum penggunaan e-filing sama dengan compliance cost setelah penggunaan $e$ filing.

$\mathrm{H}_{1}$ : Compliance cost sebelum penggunaan $e$-filing tidak sama dengan compliance cost setelah penggunaan $e$ filing.

\section{METODE PENELITIAN}

Model Analisis

Mengacu pada hubungan - hubungan yang tergambar melalui hipotesis yang telah disusun sebelumnya, maka dapat diperoleh suatu model analisis. Model analisis ini berasal dari hubungan - hubungan antara variabel yang ada, yaitu sistem e-filing dan compliance cost.

Penelitian ini akan menguji tentang perbedaan compliance cost sebelum dan sesudah pemakaian aplikasi e-filing. Model analisisnya dapat digambarkan sebagai berikut :
Sebelum

- Compliance cost

1. Direct money cost cost

2. Time cost

\section{Sesudah}

- Compliance cost

1. Direct money

2. Time cost

\section{Aplikasi $e$-filing}

\section{Definisi Operasional Variabel}

Dalam penelitian ini akan diteliti mengenai apakah ada perbedaan compliance cost sebelum dan sesudah penggunaan $e$-filing. Oleh karena itu harus diketahui indikator dari compliance cost itu sendiri, agar nantinya bisa terlihat apakah ada perbedaan pada compliance cost sebelum dan sesudah penggunaan $e$-filing.

Indikator compliance cost adalah :

\begin{tabular}{|l|l|}
\hline Compliance cost & $\begin{array}{l}\text { Indikator : } \\
\text { Direct money cost : } \\
\text { biaya pegawai bagian } \\
\text { pajak, biaya konsultan } \\
\text { pajak, biaya } \\
\text { seminar/pelatihan biaya } \\
\text { perpajakan, software } \\
\text { membeli biaya } \\
\text { perpajakan, internet, } \\
\text { telepon dan font, print, } \\
\text { biaya fotokopi, untuk } \\
\text { fax, alat tulis biaya } \\
\text { membuat SPT, bian } \\
\text { untuk menyediakan }\end{array}$ \\
\hline
\end{tabular}




\begin{tabular}{|l|l|}
\hline & tempat untuk berkas \\
pajak, biaya transportasi, \\
biaya untuk training \\
pajak bagi karyawan \\
Time cost : waktu untuk \\
ke KPP, waktu untuk \\
manajemen pajak, waktu \\
untuk antri di KPP, \\
waktu untuk mengisi \\
SPT, waktu untuk \\
membaca panduan \\
pengisian SPT, waktu \\
untuk belajar aturan \\
perpajakan yang berlaku, \\
waktu untuk mengurus \\
administrasi perpajakan. \\
\hline
\end{tabular}

\section{Skala pengukuran}

Skala pengukuran yang digunakan dalam penelitian ini adalah skala ordinal. Skala ordinal adalah skala yang memberi arti prioritas atau ranking, dimana kode yang diberikan memberikan urutan tertentu pada data, tetapi tidak menunjukkan selisih yang sama dan tidak ada nol mutlak. Skala ordinal biasanya mempergunakan analisis statistik non parametrik.

Dalam penelitian ini juga akan digunakan kuesioner untuk mengukur suatu sikap dan pendapat mengenai ada tidaknya perubahan pada compliance cost sebelum dan sesudah penggunaan aplikasi e-filing. Skala yang digunakan, seperti dijelaskan sebelumnya adalah skala ordinal. Pengukurannya dengan menggunnakan pilihan empat jawaban, yaitu "Sangat Setuju" (SS), "Setuju" (S), "Tidak Setuju" (TS), "Sangat Tidak Setuju" (STS). Untuk setiap jawaban tersebut diberi bobot nilai sebesar :

$$
\begin{aligned}
& \text { - } \quad \text { "Sangat Setuju }(\mathrm{SS})=4 \\
& \text { - } \quad \text { "Setuju" (S), = } \\
& \text { - } \quad \text { "Tidak Setuju" (TS), = } 2 \\
& \quad \text { Sangat Tidak Setuju" (STS) = } 1
\end{aligned}
$$

\section{Jenis dan Sumber Data}

Jenis data yang digunakan dalam penelitian ini adalah data kuantitatif yang merupakan data yang dapat diukur menggunakan angka. Metode kuantitatif, menurut Jane Stokes dalam bukunya How To Do Media And Cultural Studies (2003), yang diterjemahkan dalam bahasa Indonesia, adalah metode yang didasarkan pada informasi numerik atau kuantitas dan biasanya diasosiasikan dengan analisis statistik.

Sumber data yang digunakan, yaitu :

1. Data primer, yaitu data yang langsung didapatkan dari obyek penelitian, tanpa adanya perantara. Dalam penelitian ini, data primer didapat dari kuesioner

\section{Instrumen dan Pengumpulan data}

Dalam penelitian ini menggunakan metode penelitian survey, sehingga instrumen atau alat yang digunakan untuk mengumpulkan data adalah kuesioner. Pengumpulan data dilakukan dengan membagikan daftar pertanyaan yang telah disusun dalam kuesioner kepada responden, yaitu wajib pajak badan yang menggunakan aplikasi e-filing Setelah kuesioner diisi oleh responden, maka akan dikembalikan kepada penyebar kuesioner.

\section{Sampel dan Teknik Sampling}

Dalam penelitian ini yang diambil sebagai sampel adalah wajib pajak Badan yang menggunkan e-filing. Teknik pengambilan sampel yang digunakan adalah random sampling, dimana pengambilan sampel dilakukan secara acak, tanpa memperhatikan strata. Sedangkan metode pengambilan sampling yang digunakan adalah simple random sampling dimana setiap anggota populasi mendapat kesempatan yang sama untuk dipilih, tanpa memperhatikan strata yang ada, dan setiap anggota populasi hanya mendapatkan satu kali kesempatan untuk dipilih. 


\section{Teknik Analisis Data}

1. Uji Validitas

Dalam penelitian ini alat ukur yang digunakan adalah kuesioner. Kuesioner dikatakan valid apabila pertanyaan yang ada pada kuisioner mampu mengungkapkan sesuatu yang akan diukur.

Untuk menguji validitas, maka digunakan rumus :

$$
r=\frac{n \sum X Y-\sum X \sum Y}{\sqrt{\left(( n \sum X ^ { 2 } - ( \sum X ) ^ { 2 } ) \left(n \sum Y^{2}-\left(\sum Y\right.\right.\right.}}
$$

Dimana :

$\mathrm{r}=$ Koefisien korelasi Product Moment Pearson

$\mathrm{n} \quad=$ Banyaknya jumlah responden yang digunakan

$\mathrm{x}=$ Skor masing-masing item

$\mathrm{y} \quad=$ Skor total tanggapan responden atas seluruh pertanyaan

2. Uji Reliabilitas

Uji reliabilitas digunakan untuk mengetahui konsistensi dari suatu alat ukur, yaitu apakah alat ukur tersebut mempunyai hasil dengan tingkat kestabilan dan tingkat keakuratan yang tinggi dari waktu ke waktu.

Untuk mengukur reliabilitas maka digunakan rumus Alpha Cronbach, yaitu :

$$
\boldsymbol{\alpha}=\frac{k}{k-1}\left(1-\frac{\sum S^{2} j}{S^{2} x}\right)
$$

Dimana :

$\alpha=$ koefisien reliabilitas alpha cronbach

$\mathrm{k}=$ jumlah item

$\mathrm{Sj}=$ varians responden untuk skor item

$\mathrm{Sx}=$ jumlah varians skor total

Reliabilitas juga dibagi menjadi beberapa tingkatan, yaitu :

- alpha > 0,90 maka reliabilitas sempurna

- alpha antara 0,70 - 0,90 maka reliabilitas tinggi

- alpha antara 0,50 - 0,70 maka reliabilitas moderat

- alpha <0,50 maka reliabilitas rendah
3. Uji Hipotesis dengan Wilcoxon match pairs test

Uji hipotesis yang digunakan adalah Wilcoxon Match pairs test, yaitu untuk menguji hipotesis komparatif dua sampel yang berhubungan dengan data berbentuk ordinal.

Tahap - tahap melakukan uji wilcoxon :

1. Menentukan formulasi hipotesis $\left(\mathrm{H}_{1}\right.$ dan $\mathrm{H}_{0}$ )

2. Menentukan taraf nyata $(\alpha=0,05)$ untuk menentukan $\mathrm{T}$ tabel

3. Menghitung T hitung:

- Menentukan tanda beda dan besarnya tanda beda antara pasangan data

- Mengurutkan bedanya tanpa memperhatikan tanda atau jenjang

- Memisahkan tanda beda yang positif dan negatif

- Menjumlahkan semua angka positif dan angka negatif

- Menentukan nilai T hitung dengan memilih nilai $\mathrm{T}$ absolute terkecil

4. Membuat kesimpulan dengan membandingkan nilai $\mathrm{T}$ tabel dengan nilai T hitung, bila:

- $\quad$ Nilai T hitung > T tabel, maka H0 diterima

- $\quad$ Nilai $\mathrm{T}$ hitung $<$ atau $=\mathrm{T}$ tabel, maka $\mathrm{H} 1$ diterima

5. Melakukan uji signifikansi dengan rumus:

$$
z=\frac{T-\frac{1}{4} n(n+1)}{\sqrt{\frac{1}{24} n(n+1)(2 n+1)}}
$$

Dimana :

$\mathrm{n}$ = banyak data yang berubah setelah diberi perlakuan berbeda

$\mathrm{T}=$ jumlah ranking dari nilai selisih yng negatif 
(apabila banyaknya selisih yang positif lebih banyak dari banyaknya selisih negatif) atau jumlah ranking dari nilai selisih yang positif (apabila banyaknya selisih yang negatif > banyaknya selisih yang positif)

6. Mengambil kesimpulan :

- $\quad$ Bila Z hitung $>$ atau $=\mathrm{Z}$ tabel, maka perbedaan $\mathrm{n}_{1}$ dan $\mathrm{n}_{2}$ adalah signifikan

- Bila Z hitung < Z tabel, maka perbedaan perbedaan $\mathrm{n}_{1}$ dan $\mathrm{n}_{2}$ adalah tidak signifikan

Supaya mempermudah uji wilcoxon ini, maka nantinya akan digunakan program SPSS 19.0.

\section{HASIL PENELITIAN DAN ANALISIS Hasil Penelitian}

Dalam melakukan penelitian untuk mengetahui apakah ada perbedaan compliance cost sebelum dan sesudah penggunaan $e$-filing pada wajib badan digunakan kuesioner yang dibagikan pada pengguna $e$-filing. Telah didapat 50 responden yang akan mengisi kuesioner yang dikirim melalui pos.

Setelah data diterima, maka setiap jawaban diberi bobot nilai sesuai yang sudah ditentukan sebelumnya dan dapat diperoleh skor total dari jawaban setiap responden adalah :

Total Skor Kuesioner

\begin{tabular}{|l|l|l|}
\hline \multirow{2}{*}{ Responden } & \multicolumn{2}{|l|}{ Compliance Cost } \\
\cline { 2 - 3 } & Sebelum & Sesudah \\
\hline 1 & 56 & 51 \\
\hline 2 & 65 & 51 \\
\hline 3 & 64 & 49 \\
\hline 4 & 68 & 48 \\
\hline 5 & 55 & 50 \\
\hline 6 & 59 & 42 \\
\hline 7 & 66 & 50 \\
\hline 8 & 62 & 54 \\
\hline 9 & 59 & 45 \\
\hline 10 & 71 & 45 \\
\hline 11 & 62 & 42 \\
\hline 12 & 61 & 46 \\
\hline
\end{tabular}

\begin{tabular}{|c|c|c|}
\hline 13 & 60 & 50 \\
\hline 14 & 65 & 43 \\
\hline 15 & 64 & 44 \\
\hline 16 & 61 & 52 \\
\hline 17 & 72 & 45 \\
\hline 18 & 60 & 47 \\
\hline 19 & 62 & 48 \\
\hline 20 & 65 & 45 \\
\hline 21 & 65 & 51 \\
\hline 22 & 64 & 48 \\
\hline 23 & 60 & 49 \\
\hline 24 & 54 & 48 \\
\hline 25 & 65 & 47 \\
\hline 26 & 58 & 37 \\
\hline 27 & 57 & 44 \\
\hline 28 & 64 & 44 \\
\hline 29 & 60 & 49 \\
\hline 30 & 54 & 45 \\
\hline 31 & 68 & 40 \\
\hline 32 & 60 & 46 \\
\hline 33 & 63 & 50 \\
\hline 34 & 66 & 43 \\
\hline 35 & 72 & 52 \\
\hline 36 & 62 & 48 \\
\hline 37 & 59 & 37 \\
\hline 38 & 60 & 47 \\
\hline 39 & 62 & 45 \\
\hline 40 & 68 & 44 \\
\hline 41 & 62 & 49 \\
\hline 42 & 61 & 45 \\
\hline 43 & 69 & 44 \\
\hline 44 & 60 & 47 \\
\hline 45 & 59 & 41 \\
\hline 46 & 51 & 43 \\
\hline 47 & 58 & 40 \\
\hline 48 & 55 & 48 \\
\hline 49 & 64 & 46 \\
\hline 50 & 62 & 38 \\
\hline
\end{tabular}

Uji Validitas dan Reliabilitas 
Instrumen penelitian yang digunakan adalah kuesioner. Untuk mengukur apakah ada perbedaan dalam compliance cost seblum dan sesudah penggunaaan e-filing maka disusun 18 pertanyaan mengenai compliance cost sebelum dan sesudah penggunaan $e$-filing.

Maka, harus dilakukan uji validitas dan reabilitas untuk menguji apakah alat ukur, yaitu kuesioner tersebut layak, valid dan konsisten. Uji validitas dengan menggunakan rumus korelasi product moment pearson dan uji Item-Total Statistics

\begin{tabular}{|l|l|l|l|l|}
\hline & $\begin{array}{l}\text { Scale Mean if } \\
\text { Item Deleted }\end{array}$ & $\begin{array}{l}\text { Scale Variance if } \\
\text { Item Deleted }\end{array}$ & $\begin{array}{l}\text { Corrected Item- } \\
\text { Total Correlation }\end{array}$ & $\begin{array}{l}\text { Cronbach's Alpha } \\
\text { if Item Deleted }\end{array}$ \\
\hline no.1 & 58,9400 & 19,364 &, 434 &, 818 \\
no.2 & 58,6200 & 20,404 &, 111 &, 836 \\
no.3 & 58,5400 & 19,437 &, 361 &, 822 \\
no.4 & 58,7200 & 19,634 &, 266 &, 828 \\
no.5 & 58,6400 & 19,419 &, 349 &, 822 \\
no.6 & 58,4000 & 19,469 &, 356 &, 822 \\
no.7 & 58,4200 & 19,840 &, 267 &, 827 \\
no.8 & 58,4800 & 18,867 &, 493 &, 815 \\
no.9 & 58,4200 & 18,575 &, 569 &, 811 \\
no.10 & 58,4800 & 19,316 &, 386 &, 820 \\
no.11 & 58,5600 & 18,823 &, 512 &, 814 \\
no.12 & 58,5800 & 19,024 &, 467 &, 816 \\
no.13 & 58,4000 & 19,020 &, 464 &, 816 \\
no.14 & 58,4800 & 18,908 &, 483 &, 815 \\
no.15 & 58,7000 & 18,582 &, 523 &, 813 \\
no.16 & 58,4200 & 18,616 &, 559 &, 811 \\
no.17 & 58,4800 & 18,785 &, 513 &, 814 \\
no.18 & 58,3800 & 19,138 &, 439 &, 818 \\
\hline
\end{tabular}

\section{Uji validitas sebelum penggunaan aplikasi $e$-filing}

Dari tabel tersebut dapat dilihat jika hasil dari corrected item-total correlation bernilai positif. Item pertanyaan dianggap valid jika hasil corrected item-total correlation tidak ada yang bernilai negatif. Maka berdasarkan hasil tabel tersebut semua pertanyaan adalah valid. reliabilitas dengan menggunakan rumus cronbach alpha. Penghitungan uji validitas dan uji reliabilitas akan dibantu dengan menggunakan program SPSS versi 19.

Perhitungan uji validitas dan uji reliabilitas untuk pertanyaan mengenai compliance cost adalah :

- Sebelum Penggunaan aplikasi $e$ filing :
Uji reliabilitas sebelum penggunaan aplikasi e-filing

Reliability Statistics
\begin{tabular}{|l|l|}
\hline Cronbach's Alpha & N of Items \\
\hline, 827 & 18 \\
\hline
\end{tabular}

Dari tabel hasil output tersebut dapat dilihat jika nilai cronbach's alpha adalah 0,827 . Kuesioner dianggap reliabel jika $r$ alpha $>r$ tabel. Dari $r$ tabel dapat dipeoleh untuk $\mathrm{N}=50$ dan tingkat signifikansi 5\% adalah 0,279. Karena 0,827 > 0,279 maka instrumen tersebut reliabel.

- Sesudah penggunaan aplikasi $e$-filing 
Item-Total Statistics

\begin{tabular}{|c|c|c|c|c|}
\hline & \begin{tabular}{|l|} 
Scale Mean if \\
Item Deleted
\end{tabular} & $\begin{array}{l}\text { Scale Variance if } \\
\text { Item Deleted }\end{array}$ & $\begin{array}{l}\text { Corrected Item- } \\
\text { Total Correlation }\end{array}$ & $\begin{array}{l}\text { Cronbach's Alpha } \\
\text { if Item Deleted }\end{array}$ \\
\hline $\begin{array}{l}\text { no1 } \\
\text { no2 } \\
\text { no3 } \\
\text { no4 } \\
\text { no5 } \\
\text { no6 } \\
\text { no7 } \\
\text { no8 } \\
\text { no9 } \\
\text { no10 } \\
\text { no11 } \\
\text { no12 } \\
\text { no13 } \\
\text { no14 } \\
\text { no15 } \\
\text { no16 } \\
\text { no17 } \\
\text { no18 } \\
\end{array}$ & \begin{tabular}{|l}
43,4800 \\
43,4600 \\
43,4400 \\
43,5000 \\
43,4000 \\
43,5800 \\
43,6000 \\
43,3000 \\
43,3600 \\
43,4800 \\
43,4400 \\
43,5200 \\
43,6000 \\
43,4600 \\
43,7000 \\
43,5200 \\
43,5000 \\
43,3400
\end{tabular} & $\begin{array}{l}14,091 \\
14,253 \\
13,762 \\
13,847 \\
13,633 \\
13,759 \\
14,082 \\
13,071 \\
13,541 \\
13,520 \\
13,680 \\
13,193 \\
13,592 \\
13,274 \\
14,990 \\
14,459 \\
14,704 \\
13,127\end{array}$ & $\begin{array}{l}, 245 \\
, 202 \\
, 342 \\
, 310 \\
, 390 \\
, 335 \\
, 247 \\
, 623 \\
, 433 \\
, 405 \\
, 366 \\
, 495 \\
, 384 \\
, 479 \\
, 012 \\
, 143 \\
, 079 \\
, 573 \\
\end{array}$ & \begin{tabular}{|l|}
, 753 \\
, 756 \\
, 745 \\
, 747 \\
, 741 \\
, 745 \\
, 753 \\
, 724 \\
, 738 \\
, 740 \\
, 743 \\
, 732 \\
, 741 \\
, 733 \\
, 770 \\
, 761 \\
, 766 \\
, 727 \\
\end{tabular} \\
\hline . & sudah & naan & $\begin{array}{l}\text { npliance } \\
\text { iggunaan } \\
\text { eroleh dari } \\
\text { si } 19 \text { adalal }\end{array}$ & 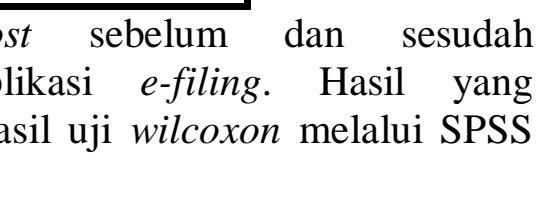 \\
\hline
\end{tabular}
positif. Item pertanyaan dianggap valid jika hasil corrected item-total correlation tidak ada yang Hasil uji Wilcoxon bernilai negatif. Maka berdasarkan has Ranks tersebut semua pertanyaan adalah valid. Uji reliabilitas sebelum penggunaan
$e$-filing

Reliability Statistics \begin{tabular}{|l|l|}
\hline Cronbach's Alpha & N of Items \\
\hline, 756 & 18 \\
\hline
\end{tabular}

\begin{tabular}{|c|c|c|c|c|}
\hline & & $\mathrm{N}$ & Mean Rank & Sum of Ranks \\
\hline $\begin{array}{l}\text { Sesudah } \\
\text { Sebelum }\end{array}$ & $\begin{array}{l}\text { - Negative Ranks } \\
\text { Positive Ranks } \\
\text { Ties } \\
\text { Total }\end{array}$ & $\begin{array}{l}50^{\mathrm{a}} \\
0^{\mathrm{b}} \\
0^{\mathrm{c}} \\
50\end{array}$ & $\begin{array}{l}25,50 \\
, 00\end{array}$ & $\begin{array}{l}1275,00 \\
, 00\end{array}$ \\
\hline
\end{tabular}

Dari tabel hasil output tersebut dapat dilihat jika nilai cronbach's alpha adalah 0,756 . Kuesioner dianggap reliabel jika $r$ alpha $>\mathrm{r}$ tabel. Dari $\mathrm{r}$ tabel dapat dipeoleh untuk $\mathrm{N}=50$ dan tingkat signifikansi 5\% adalah 0,279. Karena 0,756 > 0,279 maka instrumen tersebut reliabel.

\section{Uji Wilcoxon match pairs test}

Uji Wilcoxon digunakan untuk mengetahui apakah ada perbedaan pada

Test Statistics $^{\mathrm{b}}$

\begin{tabular}{|l|l|}
\hline & $\begin{array}{l}\text { Sesudah } \\
\text { Sebelum }\end{array}$ \\
\hline Z & $-6,159^{\mathrm{a}}$ \\
Asymp. Sig. (2-tailed) &, 000 \\
\hline
\end{tabular}

a. Based on positive ranks.

b. Wilcoxon Signed Ranks Test

Dari hasil yang diperoleh, pada tabel ranks, untuk negative ranks adalah 50, positive ranks 0 , ties 0 , yang artinya skor/nilai (compliance cost) sesudah penggunaan e-filing 
lebih kecil daripada sebelum penggunaan $e$ filing.

Pada tabel test statistics diperoleh $\mathrm{Z}$ hitung $=-6,159$. Dari $\mathrm{z}$ tabel dengan tingkat signifikansi $95 \%$ dan uji dua sisi didapat nilai 1,96

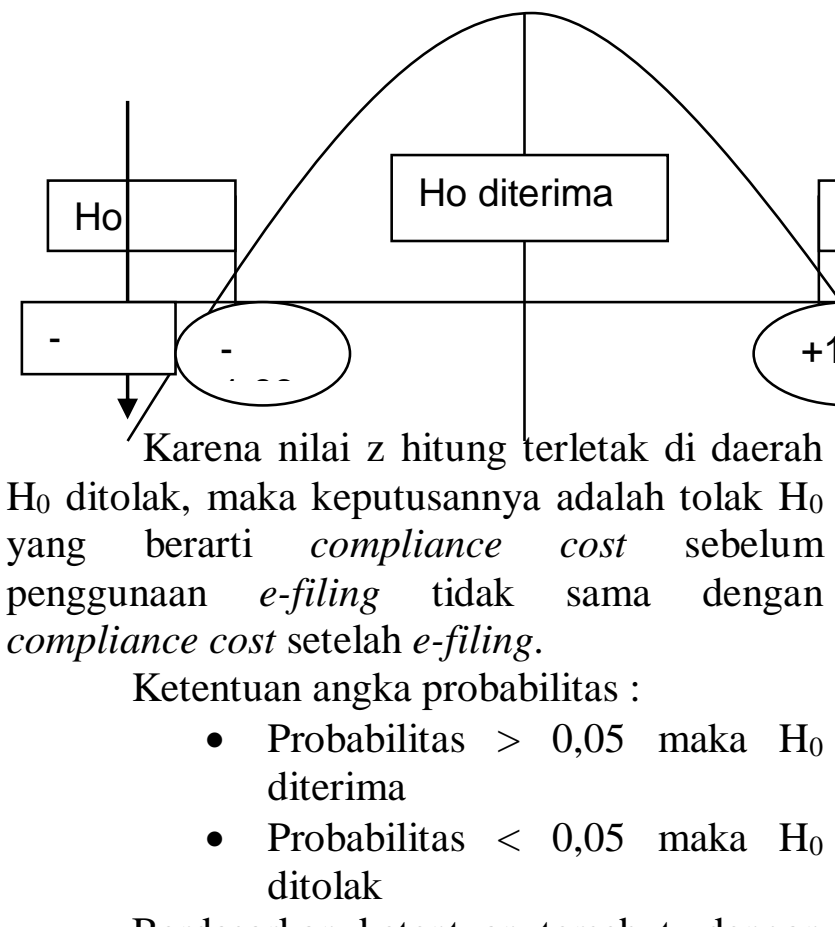

Berdasarkan ketentuan tersebut, dengan nilai asymp.sig.(2-tailed) pada tabel adalah 0,00, dimana $0,00<0,05$ maka hasilnya sama, yaitu $\mathrm{H}_{0}$ ditolak. Jadi terdapat perbedaan compliance cost sebelum dan sesudah penggunaan $e$-filing, dimana compliance cost menjadi lebih kecil.

\section{Analisis}

Temuan dan interpretasi

Dari hasil uji hipotesis yang dilakukan, dapat disimpulkan bahwa ternyata ada perbedaan pada compliance cost sebelum dan sesudah penggunaan e-filing, dimana compliance cost sesudah penggunaan aplikasi $e$ filing menjadi lebih kecil.

Hal ini tentunya agak berbeda dari penelitian sebelumnya yang menghasilkan kesimpulan bahwa tidak terdapat perbedaan yang signifikan pada compliance cost setelah penggunaan $e$-filing.
Perbedaan hasil penelitian ini dengan penelitian yang sebelumnya bisa disebabkan karena sudah ada perubahan dalam prosedur $e$ filing. Perubahan tersebut diantaranya jika sebelumnya wajib pajak yang menggunakan $e$ filing ditarik biaya pendaftaran sekarang sudah tidak ditarik lagi. Juga wajib pajak tidak perlu lagi menyampaikan SPT induk dan dokumen dokumen terkait ke KPP, seperti prosedur terdahulu, kecuali diminta oleh KPP.

Ho temuan dengan pengetahuan atau teori Dari hasil temuan yang didapat, yaitu 1,96 96 beda dengan sebelumnya, dimana compliance cost menjadi lebih rendah, maka hal inî sesuai dengan apa yang diharapkan oleh Direktorat Jendral Pajak (DJP), yaitu supaya ada pelayanan bagi wajib pajak yang cepat dan berkualitas dan bisa menekan biaya serendah mungkin, baik dari sisi wajib pajak maupun dari sisi DJP.

Hal ini bisa kita lihat dari tujuan utama penggunaan e-filing, Salah satu tujuan utama dari e-filing adalah membantu memangkas biaya dan waktu yang dibutuhkan oleh Wajib Pajak untuk mempersiapkan, memproses dan melaporkan SPT ke kantor pajak secara benar dan tepat waktu. Maka melihat dari hasil temuan yang ada, tujuan utama tersebut sudah tercapai.

\section{Kesimpulan}

Dari hasil penelitian dapat ditarik kesimpulan :

1. Penggunaan aplikasi e-filing berdampak positif terhadap penurunan compliance cost, dimana biaya yang dikeluarkan wajib pajak yang menggunakan e-filing menjadi lebih rendah.

2. Penurunan compliance cost ini juga disebabkan oleh penyederhanaan prosedur dimana wajib pajak yang menggunakan $e$-filing sudah tidak ditarik biaya lagi dan tidak perlu datang ke KPP 
lagi, kecuali ada data yang diminta oleh KPP.

3. Dengan hasil yang positif, dimana biaya yang dikeluarkan oleh wajib pajak dapat ditekan, maka Direktorat Jendral Pajak berhasil mencapai tujuan seperti yang diharapkan, yaitu memberikan pelayanan yang berkualitas dan cepat bagi wajib pajak.

\section{Keterbatasan Penelitian}

Penelitian ini terbatas hanya pada wajib pajak Badan. Untuk penelitian selanjutnya dapat meneliti wajib pajak badan serta wajib pajak orang pribadi

\section{DAFTAR REFERENSI}

Aziz, S. A., \& Idris , K. M. (2014). Does design matter in tax e-filing acceptance? . International Conference on Accounting Studies (pp. 451-457). Kuala Lumpur: Elsevier Ltd.

Azmi, A., Sapiei, N. S., \& Mustapha, M. Z. (2016). SMEs' Tax Compliance Costs and IT Adoption: The Case of a Value Added Tax. International Journal of Accounting Information Systems, 1-13.

Bruner, D. M., D'Attoma, J., \& Steinmo, S. (2017). The Role of Gender in the Provision of Public Goods Through Tax Compliance. Journal of Behavioral and Experimental Economics, 45-55.

Carter, L., Schaupp , L. C., \& McBride, M. E. (2011). The U.S. e-File Initiative: An Investigation of the Antecedents to Adoption from the Individual Taxpayers' Perspective . E-Service Journal, 2-19.

Chaouali, W., Yahia, I. B., \& Charfeddine, L. (2016). Understanding Citizens' Adoption of E-Filing in Developing Countries: An Empirical Investigation. Journal of High Technology Management Research, 161176.
Chen, J. V., Jubilado, R. J., \& Capistrano, E. P. (2015). Factors Affecting Online Tax Filling-An Application of the IS Success Model and Trust Theory. Computers in Human Behavior, 251-262.

Christian, C. R., \& Alm, J. (2014). Empathy, Sympathy, and Tax Compliance. Journal of Economic Psychology, 62-82.

Eichfelder, S., \& Schorn , M. (2009). Tax compliance costs: A business administration perspective . 1-32.

Faizal, S. M., Palil, M. R., \& Maelah, R. (2017). Perception on justice, trust and tax compliance behavior in Malaysia . Kasetsart Journal of Social Sciences, 226-232.

Fatih Y1lmaz, \& Jacqueline Coolidge. (2013). Can E-Filing Reduce Tax Compliance Costs in Developing Countries? The World Bank Investment Climate Department International Trade and Investment Unit .

Fu, J. R., Farn, C. K., \& Chao, W. P. (2006). Acceptance of Electronic Tax Filling: A Study of Taxpayer Intentions. Information \& Management, 109-126.

Ibrahim, I. (2014). The Compliance Time Costs of Malaysian Personal Income Tax System: Efilers vs. Manual-Filers . International Conference on Accounting Studies (pp. 522527). Kuala Lumpur: Elsevier Ltd.

Kotakorpi, K., \& Laamanen, J. (2016). Prelled income tax returns and tax compliance: Evidence from a natural experiment.

Lisi, G. (2014). The Interaction Between Trust and Power: Effects on Tax Compliance and Macroeconomic Implications. Journal of Behavioral and Experimental Economics, 24-33.

Lisi, G. (2015). Tax Morale,Tax Compliance and the Optimal Tax Policy . Economic Analysis and Policy, 27-32.

Mangoting, Y., Sukoharsono, E. G., \& Rosidi. (2015). Developing a Model of Tax Compliance from Social Contract 
Perspective: Mitigating the Tax Evasion . 2nd Global Conference on Business and Social Science (pp. 966-971). Bali: Elsevier Ltd.

Mendoza, J. P., Wielhouwer, J. L., \& Kirchler, E. (2017). The Backfiring Effect of Auditing on Tax Compliance. Journal of Economic Psychology, 284-294.

Mustapha, B., \& Sheikh Obid, S. B. (2014). Tax Service Quality: The Mediating Effect of Perceived Ease of Use of the Online Tax System. Global Conference on Business \& Social Science (pp. 2-9). Kuala Lumpur: Elsevier Ltd.

Pappadá, F., \& Zylberberg, Y. (2017). Austerity and Tax Compliance. European Economic Review, 506-524.

Pippin , S., \& Tosun , M. (2014). Electronic Tax Filing in the United States: An Analysis of Possible Success factors. Electronic Journal of e-Government Volume 12, 22-38.

Santhanamerya, T., \& Ramayah, T. (2012). Continued Usage Intention of E-Filing System in Malaysia: The Role of Optimism Bias. International Congress on Interdisciplinary Business and Social Science (pp. 397-403). Elsevier Ltd .

Savitri, E., \& Musfialdy. (2015). The Effect of Taxpayer Awareness, Tax Socialization, Tax Penalties, Compliance Cost at Taxpayer Compliance with Service Quality as Mediating Variable. 3rd Global Conference on Business and Social Science (pp. 682687). Kuala Lumpur: Elsevier Ltd.

Schaupp, L. C., Carter, L., \& Mcbride, M. E. (2010). E-File Adoption: A Study of US Taxpayers' Intentions. Computers in Human Behavior, 636-644.

Syed Kashif Raza Zaidi, Cassy Daniels Henderson, \& Gaurav Gupta. (2017). The Moderating Effect of Culture on E-Filing Taxes: Evidence from India. Journal of Accounting in Emerging Economies, 134-152.
Warren, N. (2016). E-Filing and Compliance Risk: Evidence From Australian Personal

Income Tax Deductions. 12th International Conference on Tax Administration, (pp. 1-21). Sydney. http://efiling.pajak.go.id/Description.aspx\#berit al diunduh pada tanggal 01

Desember 2017 